\title{
Relação lisina digestível e energia metabolizável para leitões em fase pré-inicial de creche ${ }^{1}$
}

\section{Messias Alves da Trindade $\mathrm{Neto}^{2}$, Dirlei Antonio Berto ${ }^{3}$, Ricardo de Albuquerque ${ }^{2}$, Eliana Aparecida Schammass ${ }^{4}$}

\footnotetext{
1 Trabalho realizado com o apoio da Fundação de Apoio à Pesquisa do Estado de São Paulo - FAPESP.

2 Departamento de Nutrição e Produção Animal da FMVZ-USP, Campus de Pirassununga, Rua Duque de Caxias Norte, 225, CEP: 13635-900, Pirassununga, SP.

${ }^{3}$ Departamento de Produção, FMVZ, UNESP/Botucatu, SP.

${ }^{4}$ Instituto de Zootecnia, Rua Heitor Penteado 56, CEP: 13460-000, Nova Odessa, SP.
}

RESUMO - Estudou-se a melhor relação entre lisina digestível (LIS) e energia metabolizável (EM) e efeitos no desempenho e balanço de nitrogênio em leitões na fase de creche. No desempenho foram usados 216 leitões dos 6,90 $\pm 1,11 \mathrm{~kg}$ de peso inicial aos $12 \mathrm{~kg}$, aproximadamente. No metabolismo eram 48 leitões com 9,31 \pm 2,09 kg. As concentrações de LIS eram: 1,302; 1,390 e 1,497\% e de EM: 3.510, 3.700 e $3.830 \mathrm{kcal} / \mathrm{kg}$, combinadas em um arranjo fatorial $3 \times 4$ e distribuídas em delineamento de blocos ao acaso. No desempenho dos leitões houve interação LIS EM no ganho de peso e conversão alimentar. No ganho de peso a resposta para LIS foi linear crescente nas dietas com 3.510 kcal e 3.830 kcal de EM. Na conversão alimentar observou-se efeito quadrático de LIS nas dietas que continham $3.510 \mathrm{kcal}$ e efeito linear de LIS nas dietas com $3.830 \mathrm{kcal}$ de EM. O efeito quadrático de LIS dentro de 3.510 kcal indicou 1,44\% do aminoácido digestível como nível ótimo ou a ingestão de 4,16 g LIS/Mcal de EM consumida. A resposta linear positiva na conversão alimentar ao acréscimo de LIS nas dietas com 3.830 kcal EM indica maior eficiência dos leitões ao acréscimo do aminoácido quando o nível de energia é alto. No ensaio de metabolismo o aumento de EM sugere maior retenção de $\mathrm{N}$, enquanto o acréscimo de LIS sugere menor retenção do $\mathrm{N}$ ou na relação Mcal de EM:\% LIS. A interação observada nos dois ensaios, todavia, indica que a relação LIS:EM, depende do níve energético e da característica considerada. A variação de LIS e EM na dieta indica 4 g LIS/Mcal de EM consumida, o que corresponde à ingestão diária aproximada de 7,8 g de LIS.

Palavras-chave: aminoácido digestível, desempenho, desmamados

\section{Digestible lysine:metabolizable energy ratio for nursery piglets}

\begin{abstract}
It was studied the better digestible lysine:metabolizable energy (LIS:ME) and the effects of LIS and ME levels on performance and nitrogen retention in nursery piglets. In assay 1, 216 commercial piglets from $6.98 \pm 1.16 \mathrm{~kg}$ (initial weight) at approximately $12 \pm 0.62 \mathrm{~kg}$ were used and in the assay 2, 48 similar piglets at $9.31 \pm 2.09 \mathrm{~kg}$. The LIS levels were: 1.223, $1.302,1.390$ and $1.497 \%$ and ME: 3,510, 3,700 and 3,830 kcal/kg and were assigned in $3 \times 4$ factorial arrangement and distributed in randomized block design. On piglets performance there was interaction of LIS and ME for piglets weight gain and feed:gain. The response for LIS on weight gain was linear ascendant in diets with 3,510 kcal and 3,830 kcal ME. In feed:gain was observed quadratic effect of LIS in diets with 3,510 kcal and linear effect of LIS in diets with 3,830 kcal ME. The quadratic effect of LIS in 3,510 kcal ME diets indicated as a optimal level 1.44\% of LIS or $4.16 \mathrm{~g}$ LIS/Mcal of ME. The positive linear response in feed: gain with LIS inclusion in 3,830 kcal EM diets indicated that piglets respond efficiently at amino acid increase when energy level is high. In metabolism study the ME increases suggest higher $\mathrm{N}$ retention, whereas the LIS increases suggest reduction in $\mathrm{N}$ retention or in ME Mcal:LIS \% rate. The observed interaction in two assays however indicate that LIS:ME rate depend of energetic level and considered characteristics. In present conditions the change of LIS and ME indicate $1.44 \%$ or $4 \mathrm{~g}$ LIS/Mcal ME that correspond around $7.8 \mathrm{~g}$ LIS/day of ingestion.
\end{abstract}

Key Words: digestible amino acid, performance, weaned

\section{Introdução}

A deposição de proteína no suíno em crescimento é limitada pela ingestão de energia quando as formulações são baseadas na relação lisina:energia. A energia dietética é, portanto, o principal fator que influencia as exigências de aminoácidos e limita a deposição proteica em suínos em crescimento (Roth et al., 2000). Outros fatores, não 
obstante, podem interferir na correta determinação da energia disponível (Boisen, 2003). Le Bellego \& Noblet (2002) sugeriram a relação de 4,23 g de lisina/Mcal de energia líquida em dietas com 3.380 a 3.413 kcal $/ \mathrm{kg}$ de energia metabolizável.

A eficiência de utilização do nitrogênio depende do conjunto de aminoácidos e as alterações decorrentes da deficiência de lisina resultam no catabolismo de outros aminoácidos (Salter et al., 1990). Por outro lado, concentrações de lisina acima do nível ótimo afetam o desempenho e a retenção do nitrogênio, principalmente pela redução da energia líquida ocasionada pela desaminação e eliminação do excesso de nitrogênio (Van Lunen \& Cole, 1998). Acerca da excreção de nitrogênio pelo suíno, Noblet (2003) salientou a importância dos conhecimentos sobre o uso de energia e proteína dietéticas.

Ao nascimento, o sistema digestório do suíno é imaturo e as mudanças na proporção de secreções e enzimas digestivas se refletem nos rápidos aumentos da digestibilidade de certos nutrientes, especialmente durante os dois primeiros meses de vida. As características da dieta, portanto, influenciam no desempenho do leitão nesta fase e os benefícios nutricionais advindos desse período podem refletir na idade e no peso do suíno à terminação.

As informações sobre a composição química, os valores digestíveis e metabolizáveis dos nutrientes existentes em tabelas nutricionais, por outro lado, não especificam qual a categoria animal utilizada nos estudos. São informações importantes, uma vez que a digestibilidade dos nutrientes pode variar com a idade e o peso dos animais, portanto valores nutricionais podem ser superestimados nas formulações de dietas.

Considerando que a energia metabolizável é o fator que mais limita o consumo e que a ingestão de ração pelo leitão após o desmame é baixa, objetivou-se, por meio do aumento da concentração energética da ração, determinar a melhor relação energia metabolizável (EM) e lisina digestível (LIS) para leitões na fase inicial-1 de creche com base nas características de desempenho, digestibilidade e metabolismo.

\section{Material e Métodos}

No ensaio de desempenho, foram utilizados 216 leitões machos castrados e fêmeas provenientes de granjas comerciais, com peso inicial de 6,90 $\pm 1,11 \mathrm{~kg}$. Os animais foram mantidos alojados em unidade construída em alvenaria, com pé-direito de 3,20 metros, com janelas do tipo "vitraux" nas laterais. A instalação possuía ventiladores e baias coletivas construídas em estrutura metálica, com piso plástico vazado, a $80 \mathrm{~cm}$ do piso do galpão. As baias $(1 \times 2 \mathrm{~m})$ possuíam comedouros metálicos semi-automáticos, bebedouros do tipo chupeta, aquecedores de resistência elétrica e dois termômetros, de máxima e mínima, instalados (um em cada ala) na altura do piso para auxiliar no controle da temperatura.

No ensaio de digestibilidade e metabolismo, foram utilizados 48 leitões machos castrados da mesma procedência, com 9,31 \pm 2,09 kg, para avaliação das mesmas dietas fornecidas no ensaio de desempenho. A duração dessa avaliação foi de 13 dias: 7 para adaptação dos animais às instalações e às dietas e 6 para coleta de fezes e urina. Cada animal recebeu a mesma quantidade diária de ração, com base na matéria seca, por unidade de tamanho metabólico (peso $\mathrm{kg}^{0,75}$ ). As demais medidas de manejo, coleta de fezes e urina foram obtidas segundo Barbosa et al. (1985).

A unidade de estudos de digestibilidade e metabolismo, construída em alvenaria, possuía dimensões de $20 \times 6 \mathrm{~m}$, pé-direito de $3 \mathrm{~m}$, fechada por todos os lados, janelas laterais do tipo "vitraux" revestidas em vidros e forro de isopor para isolamento térmico. A unidade encontrava-se equipada com três condicionadores de ar, do tipo "Split System”, modelo RAS 402CS + RAS 403AC, com condensação de ar e capacidade de 4,0 TR.

Em ambos os experimentos, os animais foram distribuídos em delineamento de blocos ao acaso com os tratamentos aplicados sob arranjo fatorial $3 \times 4$, de modo que o primeiro fator correspondeu à energia metabolizável e o segundo, à lisina digestível, perfazendo 12 tratamentos (dietas formuladas adotando-se as referências nutricionais do NRC 1998, Tabela 1). Adotou-se o peso inicial para formação dos blocos. No experimento de desempenho, cada tratamento foi repetido seis vezes e a unidade experimental constituída de três animais. No ensaio de digestibilidade e metabolismo, foram quatro repetições por tratamento e a unidade experimental foi um animal, alojado em gaiola semelhante à descrita por Pekas (1968).

As pesagens dos animais para controle do desempenho foram realizadas no início e ao final da fase inicial-1, durante 13 dias de experimento, e ao final da fase inicial-2, 19 dias subsequentes ao término da fase inicial-1.

Foram avaliadas as características de desempenho para ganho de peso, consumo de ração, conversão alimentar, digestibilidade aparente da matéria seca, frações aparentes da utilização do nitrogênio e da energia dietética. A taxa de eficiência de uso de lisina foi adaptada de Lilburn (2003). 
Tabela 1 - Composição centesimal das dietas fornecidas nos ensaios de desempenho e metabolismo

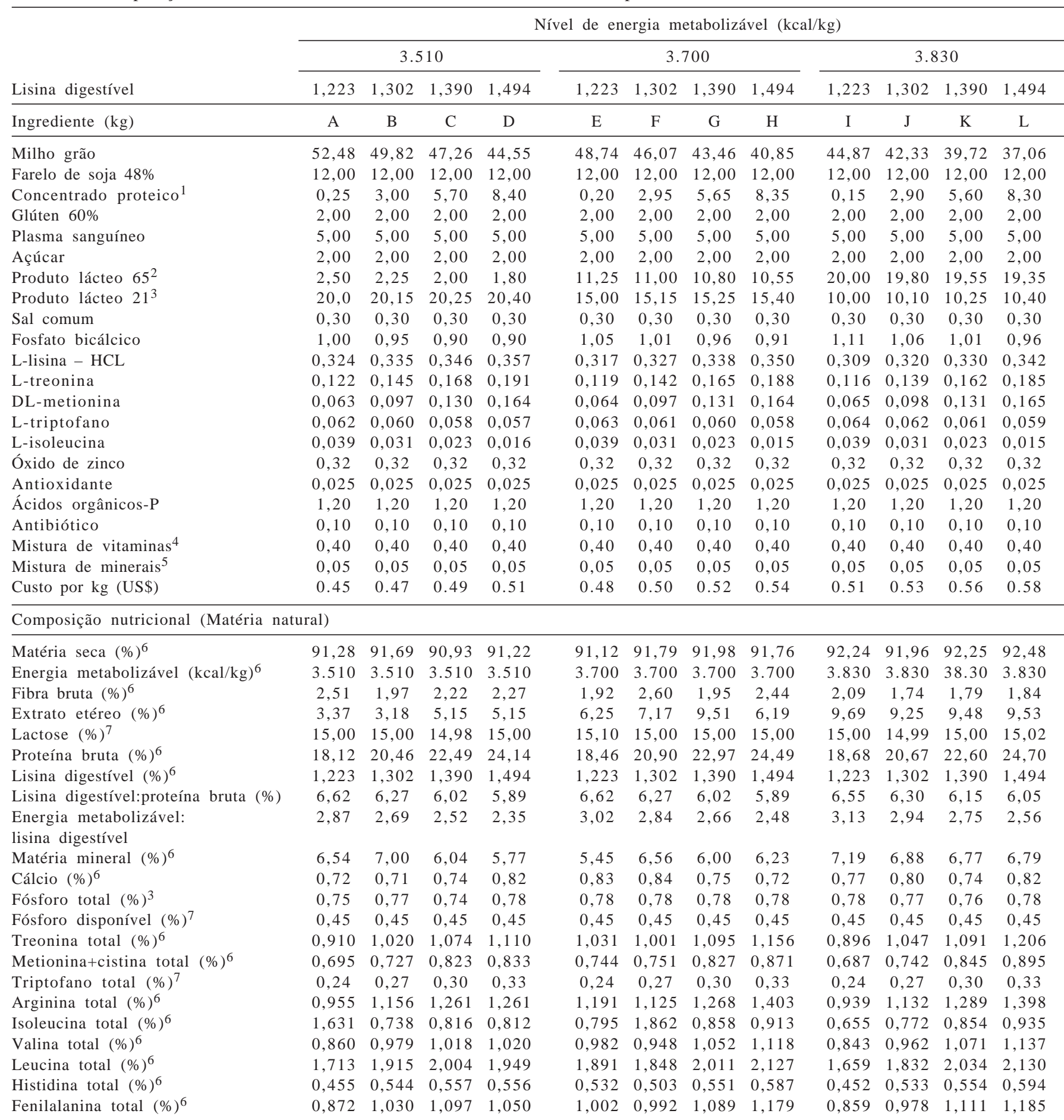

${ }^{1}$ Concentrado protéico (energia metabolizável - 3.560 kcal/kg; proteína bruta - 92\%; lisina digestível - 5,41\%; treonina digestível - 3,00\%; metionina + cistina digestível - 2,24\%; triptofano digestível - 0,846\%; isoleucina digestível - 3,57\%; valina digestível - 3,76\%; leucina digestível - 6,55\%; fenilalanina digestível - 4,358\%; tirosina digestível 3,12\%; cálcio - 0,40\%; fósforo disponível - 0,32\%.

2 Produto lácteo 65 (gordura - 40\%; lactose - 40\%; energia metabolizável - 6.498 kcal/kg; proteína bruta - 10,5\%; lisina digestível - 0,60\%; treonina digestível - 0,46\%; metionina + cistina digestível - 0,35\%; triptofano digestível - 0,09\%; cálcio - 0,25\%; fósforo disponível - 0,30\%; sódio - 0,45\%; potássio - 1,20\%.

3 Produto lácteo 21 (gordura - 5\%; lactose 70\%; energia metabolizável - $3.800 \mathrm{kcal} / \mathrm{kg}$; proteína bruta - 11,0\%; lisina digestível - 0,73\%; treonina digestível - 0,53\%; metionina + cistina digestível - 0,36\%; triptofano digestível - 0,13\%; cálcio - 0,58\%; fósforo disponível - 0,66\%; sódio - 0,80\%; potássio - 2,00\%; ácidos orgânicos$\mathrm{P}(\mathrm{Ca} 25 \%)$.

4 Por kg: vitamina A - 10.000.000 UI; vitamina D3 - 2.200.000 UI; vitamina E - 18.000 UI; vitamina K - 5.500 mg; vitamina B1 - 1.800 mg; vitamina B2 - 6.000 mg; vitamina B6 - 2.200 mg; vitamina B12 - 24.000 mg; niacina - 36.000 mg; ácido fólico - 650 mg; ácido pantotênico - 18.000 mg; biotina - 120 mg; selênio - 300 mg; antioxidante - 20 mg.

5 Por kg: manganês - $30.000 \mathrm{mg}$; zinco - $140.000 \mathrm{mg}$; cobre - $16.000 \mathrm{mg}$; ferro - $90.000 \mathrm{mg}$; cobalto - $200 \mathrm{mg}$; iodo - $850 \mathrm{mg}$.

${ }^{6}$ Níveis baseados: nas análises laboratoriais; no coeficiente estimado de digestibilidade da lisina em $88,15 \%$; no ensaio de digestibilidade e metabolismo ocorrido previamente ao ensaio de desempenho.

7 Níveis calculados. 
As análises estatísticas das variáveis experimentais foram realizadas pelo pacote computacional SAS (1996), segundo o modelo matemático a seguir.

$$
\mathrm{Y}_{\mathrm{ijk}}=\mu+\mathrm{E}_{\mathrm{i}}+\mathrm{L}_{\mathrm{j}}+\mathrm{EL}_{\mathrm{ij}}+\mathrm{B}_{\mathrm{k}}+\mathrm{e}_{\mathrm{ijk}} \text {, }
$$

em que: $\mathrm{Y}_{\mathrm{ijk}}=$ constante associada a todas as observações, durante os experimentos de desempenho, digestibilidade e metabolismo; $\mu$ = média geral da variável; $\mathrm{E}_{\mathrm{i}}=$ efeito do nível i de energia, em que i = 3.510, 3.700 e 3.830 kcal de EM/ kg de ração; $L_{j}=$ efeito do nível j de lisina, em que j = 1,20; 1,302; 1,3900 e 1,494\% de lisina digestível; $\mathrm{EL}_{\mathrm{ij}}=$ efeito da interação dos fatores i e j; $\mathrm{B}_{\mathrm{k}}=$ efeito do bloco k, de modo que $\mathrm{k}=1,2, \ldots 6$ (desempenho) e $1,2, \ldots 4$ (digestibilidade e metabolismo); eij $_{\mathrm{k}}=$ erro aleatório associado a cada observação.

Na fase inicial-2 do ensaio de desempenho, a partir de $11,90 \pm 1,90 \mathrm{~kg}$, os leitões receberam mesma dieta padrão. Nessa etapa, avaliaram-se os prováveis efeitos residuais dos tratamentos no desempenho dos animais.

\section{Resultados e Discussão}

As temperaturas nos períodos experimentais foram: ensaio 1 - máxima $25,7 \pm 2,1$ e mínima $17,6 \pm 1,4{ }^{\circ} \mathrm{C}$. Nos resultados do desempenho (Tabela 2), constataram-se altos coeficientes de variação, o que é comum em experimentos com suínos nessa fase da produção. Após o desmame, feito em idade antecipada, o leitão encontra-se sob estresse multifatorial, que impõe grandes mudanças fisiológicas até que se adapte a essa nova fase da criação. Em curto período de fornecimento das dietas experimentais, como ocorreu neste estudo, a variação individual entre animais normalmente afeta o desempenho e os efeitos dos tratamentos nessa fase considerada de transição nutricional para o suíno jovem.

Houve interação $(\mathrm{P}<0,01)$ lisina digestível e energia metabolizável no peso final, no ganho de peso, no ganho de peso relativo, no consumo de ração, na conversão alimentar e no consumo de lisina $(\mathrm{P}<0,05)$ dos leitões (Tabelas 2 e 3). O ganho de peso teve resposta linear crescente $(\mathrm{P}<0,01)$ à concentração de lisina na dieta, com $3.830 \mathrm{kcal}(16.53 \mathrm{~J})$ sugerindo-se também efeito $(\mathrm{P}=0,08)$ na dieta com $3.510 \mathrm{kcal}(14,67 \mathrm{~J})$ de energia metabolizável. No entanto, independentemente do nível de lisina, o ganho relativo reduziu com aumento da concentração de energia metabolizável na dieta $(\mathrm{P}<0,01)$, o que evidencia piora do desempenho conforme foi aumentada a concentração de energia.

Sobre o consumo de ração, também ficou caracterizada $(\mathrm{P}<0,05)$ interação lisina e energia metabolizável. No maior nível de energia (3.830 kcal), o aumento da concentração

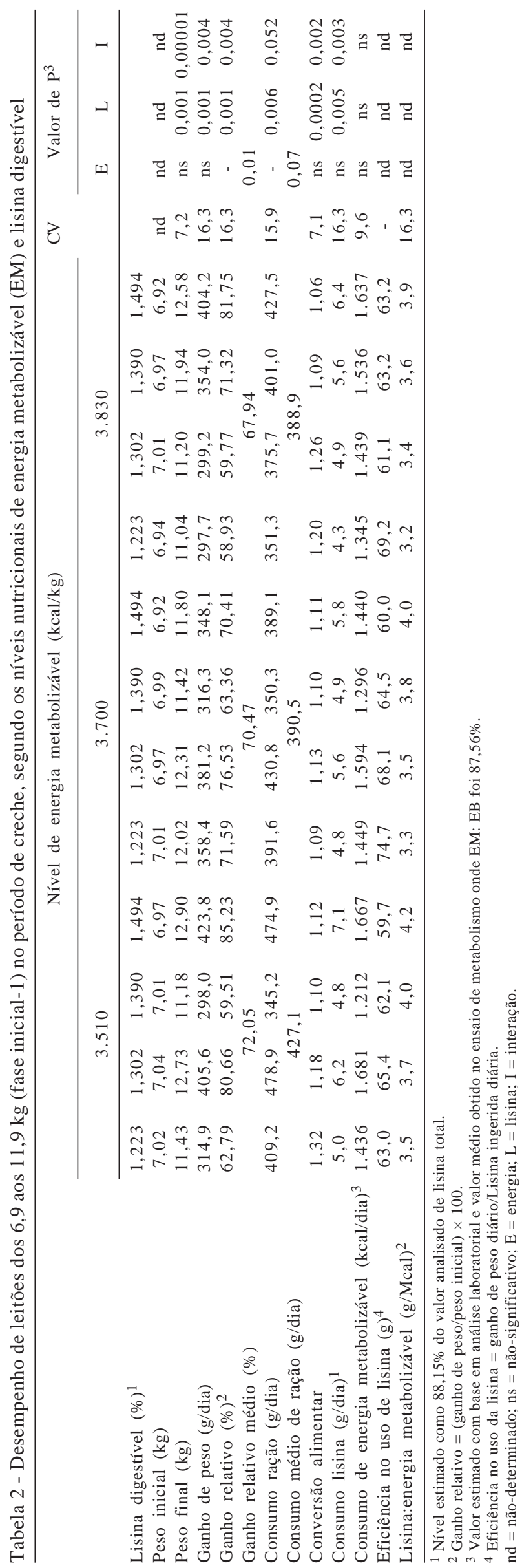

(c) 2009 Sociedade Brasileira de Zootecnia 
Tabela 3 - Equações de regressão indicando efeito do nível de lisina digestível no experimento de desempenho na fase inicial-1

\begin{tabular}{lcr}
\hline Variável & Equação de regressão & Valor de $\mathrm{P}$ \\
\hline Lisina no nível 3.830 kcal de EM & $\hat{\mathrm{Y}}=6,583581+3,582788 \mathrm{X}$ & 0,001 \\
Ganho de peso $(\mathrm{kg})$ & $\hat{\mathrm{Y}}=-0,018492+0,2506112 \mathrm{X}$ & 0,95 \\
Lisina no nível 3.830 kcal de EM & $\hat{\mathrm{Y}}=0,684752-0,000076 \mathrm{X}$ & 0,001 \\
Consumo de ração $(\mathrm{kg})$ & & 0,04 \\
Conversão alimentar & $\hat{\mathrm{Y}}=5,301501-5,407778 \mathrm{X}+1,740741 \mathrm{X}^{2}$ & 0,78 \\
Lisina no nível 3.510 kcal de EM & $\hat{\mathrm{Y}}=1,703167-0,385556 \mathrm{X}$ & 0,997 \\
Lisina no nível 3.830 kcal de EM & 0,0005 \\
\hline
\end{tabular}

do aminoácido dietético determinou resposta linear $(\mathrm{P}=0,006)$ ascendente no consumo de ração. Isoladamente, o fator energia metabolizável indicou $(\mathrm{P}=0,07)$ menor ingestão voluntária de alimento conforme aumentou o nível de energia da dieta.

A importância da energia dietética como principal fator de influência nas exigências de aminoácidos foi destacada por Boisen (2003), que observou que a deposição de proteína do suíno poderia ser limitada até cerca de 40 kg de peso. Assim, a composição ótima de aminoácidos digestíveis está relacionada à energia da dieta, embora outros fatores também possam interferir. O uso de ingredientes com alta digestibilidade como fonte proteica e de energia em dietas para leitões na fase inicial-1 também é um aspecto a ser considerado, como enfatizaram Tokach et al. (1995), Thacker (1999) e Trindade Neto et al. (2002).

Na conversão alimentar, houve efeito $(\mathrm{P}<0,05)$ quadrático do nível de lisina nas dietas com $3.510 \mathrm{kcal}$ (14,67 J), o que indica o nível de 1,55\% do aminoácido digestível como nível ótimo ou a ingestão de 4,48 g lisina/ Mcal (1,07g/MJ) de energia metabolizável consumida. Os valores correspondentes de lisina, com base na análise dos aminoácidos e estimados como 88,15\% da lisina total, seriam: 1,44\% digestível ou 4,16 g LIS/Mcal (0,99g/MJ) de EM consumida. No nível $3.830 \mathrm{kcal}$ (16.53 J) de energia metabolizável, entretanto, a resposta foi linear positiva na conversão alimentar, em resposta ao acréscimo de lisina nas dietas, o que indica que os leitões responderam mais eficientemente ao acréscimo do aminoácido quando o nível de energia foi mais elevado. A melhoria na conversão alimentar em resposta ao nível de lisina neste estudo confirma observações de Williams et al. (1997), Trindade Neto et al. (2000), De Rouchey et al. (2003) e Tokach et al. (2003).

Usando leitões do desmame (14 dias) aos 28 e 56 dias de idade, Beltranema et al. (1997) constataram que relações de 2,7 a 4,2 g de lisina/Mcal de enrgia digestível permitiram melhora linear no desempenho, sem diferenças significativas na ingestão de alimento. Esses autores concluíram, entretanto, que o maior nível de lisina não foi suficiente para atender ao máximo desempenho e sugeriram novos estudos para caracterizar as verdadeiras respostas das demandas de lisina e energia. Van Lunen \& Cole (1998) forneceram níveis de lisina total de 0,85 a 2,29\% para leitões dos 9,0 aos 25,0 kg e determinaram para o máximo desempenho 4,18 g LIS/Mcal de energia digestível.

As respostas para ganho de peso, consumo de ração e conversão alimentar foram semelhantes às obtidas em recentes estudos com leitões desmamados em condições parecidas. Trabalhando com leitões dos 5 aos 9 kg, De Rouchey et al. (2003) obtiveram aumentos lineares no ganho de peso e na eficiência alimentar fornecendo níveis dietéticos de 1,4 a $1,80 \%$ de lisina total e de 1,23 a $1,59 \%$ de lisina digestível, segundo a relação do NRC (1998).

No consumo de lisina, ficou caracterizada interação lisina $\times$ energia metabolizável. Evidenciou-se aumento linear na ingestão de lisina nas dietas com maior nível de energia (3.830 kcal de EM). Esse aumento da ingestão de lisina era previsível, em decorrência do acréscimo do aminoácido na dieta e da tendência desse aumento também nos demais níveis de energia $(\mathrm{P}=0,08)$. $\mathrm{O}$ aumento de energia metabolizável e lisina na dieta, por outro lado, não teve efeitos significativos na ingestão diária de energia pelos leitões.

Apesar de a eficiência de uso da lisina não ter sido avaliada estatisticamente, os dados médios calculados (Tabela 2) apontam para o menor nível do aminoácido. O maior consumo de lisina e a redução da eficiência no uso do aminoácido, embora não obedeça a uma relação proporcional, torna-se um indicador do custo/benefício. A partir dessa avaliação, é possível avaliar quanto da suplementação de lisina torna-se favorável ao ganho de peso e ao custo da dieta e de produção do suíno em suas respectivas fases. Tokach et al. (2003) constataram resposta linear no ganho de peso e quadrática na eficiência alimentar ao determinarem o nível ótimo de lisina para leitões entre 


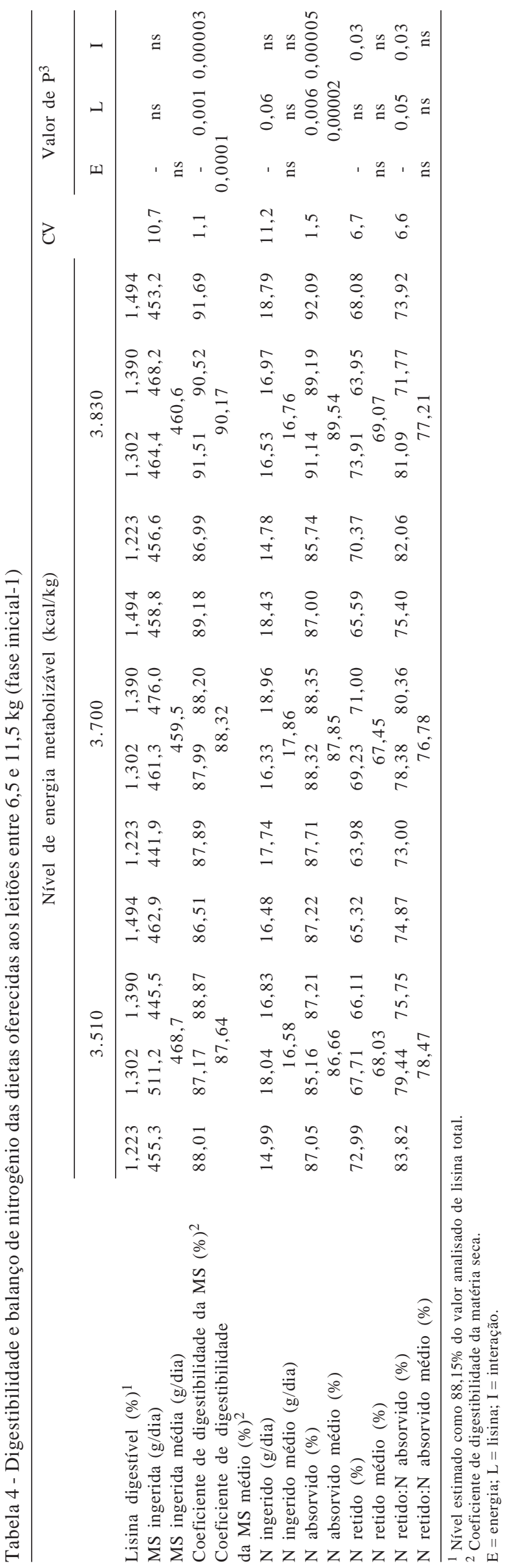

7 e $11 \mathrm{~kg}$ oferecendo dietas com 3,45 Mcal de energia digestível e níveis digestíveis de 1,22 a 1,62\% do aminoácido. Ao considerarem a viabilidade econômica das dietas, entretanto, propuseram 1,42\% de lisina digestível.

Na avaliação da digestibilidade, não houve interação nem efeitos dos fatores energia metabolizável e lisina na matéria seca ingerida (Tabelas 4 e 5). Em análise do coeficiente de digestibilidade aparente da matéria seca (DAMS), verificou-se interação ( $\mathrm{P}=0,00003)$ das concentrações de energia metabolizável e de lisina. O aumento linear da digestibilidade de acordo com os níveis de energia metabolizável $(P=0,00001)$ foi mais evidente nas dietas com 1,302\% ( $\mathrm{P}=0,0001), 1,390 \%(\mathrm{P}=0,02) \mathrm{e}$ 1,494\% ( $\mathrm{P}=0,0001)$ de lisina.

Considerando a variação de lisina dentro de cada concentração de energia metabolizável, sugere-se efeito linear $(P=0,06)$ crescente da digestibilidade aparente de matéria seca com o aumento da concentração do aminoácido no nível 3.700 kcal de energia metabolizável. Nas dietas com 3.830 kcal de EM, a resposta ao aumento de lisina foi quadrática $(\mathrm{P}<0,01)$ sobre a digestibilidade aparente da matéria seca.

O aumento da energia coincidiu com o da digestibilidade aparente da matéria seca até certo nível de lisina, nesse caso para 3.830 kcal de EM, a equação de regressão indica como nível ótimo de lisina 1,54\%, entretanto, para os níveis analisados do aminoácido, o nível indicado seria 1,40\% do aminoácido digestível.

Considerando as características satisfatórias das dietas empregadas, pode-se afirmar que a variação crescente na concentração de energia e aminoácidos teria favorecido a digestibilidade da dieta. $\mathrm{O}$ aumento da digestibilidade provavelmente estaria associado ao gradativo acréscimo do substrato energético e proteico no trato digestivo que induziriam aumento na secreção enzimática. Por outro lado, a fração digestível não implica retenção do aminoácido digestível absorvido (Mosenthin \& Rademacher, 2003) (Tabela 4).

Na fração absorvida do nitrogênio(N absorvido), ocorreram efeitos dos fatores energia metabolizável $(\mathrm{P}=0,00002)$ e lisina $(P=0,006)$ e interação $(P=0,0001)$. O acréscimo de energia metabolizável promoveu aumento do nitrogênio absorvido e essas respostas se destacaram nas dietas com $1,302 \%$ ( $\mathrm{P}=0,00001)$; com $1,390 \%$ ( $\mathrm{P}=0,04)$; e com $1,494 \%$ de lisina $(\mathrm{P}=0,0001)$. No entanto, ao considerar os efeitos de lisina dentro do fator energia metabolizável, a variação do teor de aminoácido produziu efeito $(P=0,0001)$ apenas nas dietas com $3.830 \mathrm{kcal} / \mathrm{kg}$ de energia metabolizável, quando houve aumento linear no nitrogênio absorvido. 
Tabela 5 - Equações de regressão indicando efeito do nível de lisina digestível no experimento de digestibilidade e metabolismo na fase inicial-1

\begin{tabular}{|c|c|c|}
\hline Variável & Equação de regressão & $\mathrm{R}^{2}$ \\
\hline \multicolumn{3}{|c|}{ Coeficiente de digestíbilidade da matéria seca (\%) } \\
\hline Lisina no nível 3.700 kcal de EM & $\hat{\mathrm{Y}}=84,4247+2,73000 \mathrm{X}$ & 0,80 \\
\hline Lisina no nível 3.830 kcal de EM & $\hat{Y}=3,2545+114,73265 X-37,194497 X^{2}$ & 0,79 \\
\hline \multicolumn{3}{|l|}{ Nitrogênio absorvido (\%) } \\
\hline Lisina no nível 3.830 kcal de EM & $\hat{Y}=73,30149+11,39501 X$ & 0,62 \\
\hline \multicolumn{3}{|l|}{ Nitrogênio retido (\%) } \\
\hline Lisina no nível 3.510 kcal de EM & $\hat{\mathrm{Y}}=91,3895-16,39001 \mathrm{X}$ & 0,85 \\
\hline Lisina no nível 3.700 kcal de EM & $\hat{\mathrm{Y}}=-176,0111+341,97019 \mathrm{X}-118,44451 \mathrm{X}^{2}$ & 0,98 \\
\hline \multicolumn{3}{|l|}{$\mathrm{N}$ retido/N absorvido (\%) } \\
\hline Lisina no nível 3.510 kcal de EM & $\hat{\mathrm{Y}}=107,45501-20,34167 \mathrm{X}$ & 0,93 \\
\hline Lisina no nível 3.700 kcal de EM & $\hat{\mathrm{Y}}=-161,87181+333,38507 \mathrm{X}-114,83336 \mathrm{X}^{2}$ & 0,98 \\
\hline Lisina no nível 3.830 kcal de EM & $\hat{\mathrm{Y}}=109,2695-22,498335 \mathrm{X}$ & 0,72 \\
\hline
\end{tabular}

Os resultados confirmam as observações anteriores sobre o aumento da digestibilidade aparente da matéria seca com o acréscimo de aminoácido e sobre as características biológicas das dietas quanto à absorção do nitrogênio. Destacam-se, entretanto, as observações de Close (1994) de que os aminoácidos não são utilizados com mesma eficiência de absorção. Individualmente, cada aminoácido tem uma taxa de reutilização proveniente da degradação protéica.

Na retenção do nitrogênio ( $\mathrm{N}$ retido), houve interação $(P=0,03)$ de energia metabolizável e lisina. A variação crescente de energia metabolizável sugere aumento linear $(P=0,06)$ do nitrogênio retido apenas na concentração dietética 1,302\% de lisina. Em relação à variação de lisina em cada concentração de energia metabolizável, observou-se que, nas dietas com $3.510 \mathrm{kcal}$, o aumento de lisina determinou a redução $(P=0,02)$ do nitrogênio retido. Essa observação coincide com a diminuição da relação Mcal:\%lisina (2,86; 2,69; 2,52; 2,35). A variação de lisina nas dietas com 3.700 kcal de energia metabolizável, não obstante, propiciou efeito quadrático $(P=0,03)$ no nitrogênio retido. Nas dietas com 3.830 kcal de energia metabolizável, os níveis de lisina não propiciaram diferenças significativas no nitrogênio retido.

A resposta quadrática para a variação de lisina no nível 3.700 kcal de energia metabolizável indicou como ótima a concentração de 1,44\% do aminoácido, o que corresponde a ingestão diária de aproximadamente 7,78 g de lisina ou 3,99 g de lisina/megacaloria (Mcal) de energia metabolizável. Ressalta-se, porém, que esse resultado obtido em estudo de metabolismo ocorreu quando as condições de manejo e de ambiente (interna às instalações) estavam sob melhor controle, situação diversa da apresentada no ensaio de desempenho, sobretudo em relação ao gasto de energia.
A interação de energia e lisina foi observada por Urynec \& Buraczewska (2003) ao determinarem a relação ótima entre lisina digestível e energia metabolizável, bem como os efeitos desses nutrientes no balanço de nitrogênio e no desempenho de leitões após o desmame. Esses autores constataram interação energia $\times$ lisina para o aumento da retenção do nitrogênio, e que a maior retenção do nitrogênio foi associada à ingestão do nitrogênio e favorecida pelo acréscimo energético da dieta e o aumento de energia metabolizável correspondeu ao maior ganho de peso e eficiência alimentar.

Considerando isoladamente o fator lisina, o efeito ocorreu positivamente, até certo ponto, nas dietas com $3.700 \mathrm{kcal}$ de energia. Essa resposta complementa as informações de Trindade Neto et al. (2000), que constataram efeito linear na retenção de nitrogênio utilizando níveis totais de lisina que variavam de 0,85 a 1,25\% em leitões de 10,8 $\pm 1,4 \mathrm{~kg}$ e concluíram que a demanda pelo nutriente estava acima dos níveis estudados. Neste caso, o aumento dos níveis e da ingestão de lisina não esteve relacionado à retenção do nitrogênio dietético, uma vez que o ponto ótimo ocorreu abaixo do maior nível estudado, o que ratifica as considerações de Close (1994).

Van Lunen \& Cole (1998) observaram que níveis de lisina acima do ótimo afetam o desempenho e a retenção desse componente. Esse prejuízo deve-se principalmente à redução da energia líquida, que, em parte, é utilizada no catabolismo do excesso de aminoácidos. Noblet (2003) ratificou que a suplementação de aminoácidos livres em dietas exige conhecimento acurado sobre a utilização da energia e da proteína e sugeriram novos estudos sobre o assunto.

Sobre o nível ótimo $(1,44 \%)$ de lisina digestível determinado com a retenção do nitrogênio na dieta com 3.700 kcal 
de EM, confirma-se a indicação de Tokach et al. (2003), que empregaram níveis semelhantes do aminoácido em dietas para leitões dos 7 aos $11 \mathrm{~kg}$ e recomendaram 1,42\%. Nesta comparação, a diferença está relacionada à energia das dietas fornecidas, nas quais os autores usaram 3,45 Mcal de energia digestível.

Quando considerada a relação $\mathrm{N}$ retido: $\mathrm{N}$ absorvido, ou valor biológico, as respostas praticamente confirmaram o ocorrido na variável nitrogênio retido, havendo efeito do fator lisina $(\mathrm{P}<0,05)$ e interação $(\mathrm{P}=0,04)$ dos níveis de energia metabolizável e lisina. A indicação de redução do valor biológico $(\mathrm{P}<0,01)$ ficou confirmada nas dietas com 3.510 e $3.830 \mathrm{kcal}$ de EM com o aumento dos níveis de lisina. Da mesma forma, a variação de lisina nas dietas com 3.700 kcal de EM confirmou o aumento $(\mathrm{P}<0,05)$ do valor biológico até o ponto ótimo de 1,45\% de lisina digestível. Considerações nesse sentido são as mesmas apresentadas para a retenção do nitrogênio acerca da qualidade da dieta e da ingestão diária do aminoácido associada à energia dietética. Desse modo, o valor aproximado de 7,78 g/dia de lisina em dieta com $3.700 \mathrm{kcal}$ de EM deve assegurar ingestão diária de 3,99 g de lisina digestível/Mcal de energia metabolizável consumida.

Boisen (2003) destacou a relevância na determinação do valor biológico em dietas completas e atribuiu menor importância para as fontes alimentares. Em revisão, Heger (2003) fez as seguintes considerações: a retenção de nitrogênio depende do nível dos aminoácidos não-essenciais que são mais facilmente convertidos no metabolismo; a conversão da arginina e da lisina em não-essenciais seria mais difícil; dietas com baixa quantidade de aminoácidos não-essenciais demandam menor quantidade de aminoácidos essenciais, como arginina, lisina, e aminoácidos sulfurados, para melhor retenção do nitrogênio, uma vez mantida a concentração do nitrogênio; arginina, lisina e os aminoácidos sulfurados são as piores fontes de não-essenciais, fundamentais ao metabolismo; o excesso dos essenciais teria efeito adverso no processo anabólico proteico (deposição), entendendo-se que o efeito adverso não é inabilidade para a síntese dos não-essenciais; determinados cuidados devem ser tomados ao reduzir o nível proteico das dietas e fazer uso dos aminoácidos industriais.

Sobre o desequilíbrio dietético dos aminoácidos, D’Mello (2003) destacou que no tecido (sítio de síntese) isso ocorre quando o aminoácido suplementar é absorvido mais rapidamente que os demais ligados à proteína do ingrediente. Nesse caso, a concentração de lisina plasmática livre aumenta 1 a 2 horas após a ingestão da dieta com o aminoácido puro, enquanto, com os outros aminoácidos provenientes da proteína, o pico ocorre entre 2 e 6 horas da alimentação. Se o suíno é alimentado uma vez ao dia ou em intervalos longos, como neste estudo, poderá estar caracterizado o desequilíbrio celular dos aminoácidos. Assim, o crescimento e a eficiência da utilização dos nutrientes são prejudicados, daí a importância da alimentação livre e da frequência de alimentação. Neste ensaio de metabolismo, poderia estar caracterizada alguma dessas situações metabólicas, uma vez que os animais foram alimentados duas vezes ao dia em intervalo de aproximadamente oito horas.

Outros fatores de impacto no metabolismo proteico e nos consequentes resultados foram descritos por Mosenthin \& Rademacher (2003) e Moughan \& Fuller (2003). Entre eles, idade, genética, ambiente e estágio fisiológico, composição da dieta, nível de alimentação, balanço de aminoácido, nível de proteína dietética, nível de energia, cronologia da aparente absorção dos aminoácidos nos tecidos e os métodos experimentais. Esses autores concluíram que variações na digestibilidade aparente, em relação ao nível de proteína e aminoácidos dietéticos, consistem na hipótese de perda endógena não-específica, que é proporcional à ingestão de matéria seca e não propriamente ao nível de ingestão proteica e/ou de aminoácido.

Segundo Noblet (2003), a mensuração dos efeitos da manipulação proteica dietética com uso de aminoácidos livres, quanto à excreção e retenção de nitrogênio, demanda estratégias e critérios adequados ou acurados de avaliação da proteína e da energia. Esse autor propôs estudos para entender a regulação da ingestão de alimento, associada à quantidade e qualidade dos aminoácidos supridos, uma vez que níveis acima do ótimo afetam o desempenho e a retenção deste componente pelo animal e esse prejuízo deve-se principalmente à redução da energia líquida, que, em parte, é utilizada no catabolismo e na eliminação do excesso dos aminoácidos.

Considerando os resultados de desempenho, o nível de lisina digestível indicado para leitões entre 6,90 e 11,90 kg seria próximo a $1,44 \%$, todavia o componente energia é fundamental no aporte desse nutriente. Assim, na determinação da exigência de lisina, deve-se ater ao nível de ingestão, em torno de 4,16 g de lisina digestível/Mcal de energia metabolizável.

Detendo-se à relação e ao consumo da dieta a ser oferecida, é possível estabelecer os níveis desejáveis de lisina e energia. A eficácia de utilização da dieta, por sua vez, depende de sua qualidade biológica e da sua variação proteica de acordo com os níveis de lisina. Neste caso, a variação da proteína pode ter interferido nas respostas de digestibilidade, metabolismo e desempenho dos leitões, sugerindo-se maiores critérios nesse tipo de avaliação. 
Na fase inicial-2 (Tabela 6), não ficaram caracterizados efeitos residuais dos tratamentos aplicados na fase anterior (Inicial-1). Os animais que anteriormente tiveram menor desempenho se igualaram em massa corporal quando receberam a dieta padrão.

No período subsequente aos tratamentos experimentais, há um limite fisiológico na recuperação dos leitões não estabelecido pela pesquisa, no qual o déficit de nutrientes dietéticos, por determinado período, não compromete o desempenho seguinte do animal. Nesse período, o suíno pode recuperar o limitado desempenho de uma fase curta, imediatamente anterior, se as demais condições de meio e experimental forem satisfatórias. Uma vez que todas as dietas empregadas na fase inicial-1 apresentavam boa qualidade biológica e foram fornecidas em curto período, os efeitos sobre os leitões rapidamente foram diluídos na fase seguinte.

Tabela 6 - Desempenho dos leitões na fase inicial-2 de creche dos 11,5 aos 21,9 kg e no período total dos 6,5 aos 21,9 kg

\begin{tabular}{|c|c|c|c|c|c|c|c|c|}
\hline \multirow{3}{*}{$\begin{array}{l}\text { Variável } \\
\text { Dos } 11,5 \text { aos } 21,9 \mathrm{~kg}^{1}\end{array}$} & \multicolumn{8}{|c|}{ Nível nutricional aplicado dos 6,5 aos $11,5 \mathrm{~kg}$} \\
\hline & \multicolumn{4}{|c|}{ Lisina digestível (\%) } & \multicolumn{3}{|c|}{ Energia metabolizável (kcal/kg) } & \multirow{2}{*}{$\begin{array}{c}\text { CV } \\
\%\end{array}$} \\
\hline & $1,223 *$ & $1,302 *$ & $1,390 *$ & $1,494 *$ & 3510 & 3700 & 3830 & \\
\hline Peso final (kg) & 21,57 & 21,56 & 22,12 & 22,53 & 21,96 & 21,81 & 22,05 & 8,4 \\
\hline Ganho de peso médio (g/dia) & 528,7 & 511,3 & 556,1 & 556,2 & 543,6 & 516,1 & 554,5 & 13,5 \\
\hline Consumo de ração médio (g/dia) & 988,7 & 997,0 & 989,8 & 1012,3 & 989,3 & 985,7 & 1014,7 & \\
\hline Conversão alimentar & 1,87 & 1,95 & 1,78 & 1,82 & 1,82 & 1,91 & 1,83 & 8,1 \\
\hline Ganho de peso médio (g/dia) & 441,7 & 441,1 & 456,8 & 467,8 & 452,9 & 445,2 & 457,4 & 12,4 \\
\hline Consumo de ração médio (g/dia) & 725,1 & 742,6 & 722,4 & 746,1 & 731,2 & 730,4 & 740,5 & 12,8 \\
\hline Conversão alimentar & 1,65 & 1,69 & 1,59 & 1,60 & 1,62 & 1,65 & 1,63 & 10,4 \\
\hline
\end{tabular}

${ }^{1}$ Efeitos subsequentes à aplicação dos tratamentos na fase inicial-1 dos 6,5 aos 11,5 kg (P>0,05).

* Nível estimado como $88,15 \%$ da lisina total na fase inicial-1.

\section{Conclusões}

A relação lisina digestível:energia metabolizável depende do nível energético e da característica considerada. O aumento da energia na dieta deve ser acompanhado do aumento da lisina e dos demais aminoácidos para atender o crescimento. O aumento da concentração de energia metabolizável não favorece a retenção do nitrogênio dietético, enquanto o acréscimo de lisina sugere redução na retenção ou na relação Mcal de energia metabolizável:\% lisina digestível. A relação entre lisina digestível:energia metabolizável, obtida em análise das características de desempenho e de metabolismo, é fundamental no estabelecimento das exigências desses nutrientes para leitões na fase inicial-1 do crescimento pósdesmame. Nas condições deste estudo, indica-se $4 \mathrm{~g}$ lisina/Mcal (0,99g/MJ) de energia metabolizável consumida.

\section{Agradecimentos}

À Ajinomoto Biolatina Indústria e Comércio Ltda.

\section{Literatura Citada}

BARBOSA, H.P.; PEREIRA, J.A.A.; COSTA, P.M.A. et al. Exigência de proteína bruta para leitões na fase inicial de crescimento (5 a $15 \mathrm{~kg}$ de peso). Revista Brasileira de Zootecnia, v.14, n.1, p.45-52, 1985.

BELTRANEMA, E.; PATIENCE, J.F.; ORR, A. et al. Lysine for early weaned piglets. Defining the response of early weaned piglets to dietary lysine:energy ratios. Prairie Swine Centre, 1997. p.22-25. (Annual Research Report).

BOISEN, S. Ideal dietary amino acid profiles for pigs In: D’MELLO, J.P.F. (Ed.) Amino acids in animal nutrition. 2.ed. Edinburgh: CABI Publishing, 2003. p.157-168.

CLOSE, W.H. Feeding new genotypes establishing amino acid/energy requirements. In: COLE, D.J.A.; WISEMAN, J.; VARLEY, M.A. (Eds.) Principles of pig science. Nottinghan: Redwood Books, 1994. p.123-140.

D’MELLO, J.P.F. Adverse effects of amino acid. In: D’MELLO, J.P.F. Amino acids in animal nutrition. 2.ed. Edinburgh: CABI Publishing, 2003. p.187-202.

DE ROUCHEY, J.M.; DRITZ, S.S.; TOKACH, M.D. et al. Effects of increasing dietary lysine in transition diets on nursery pig growth performance. Swine Day, p.39-42, 2003.

HEGER, J. Essential to non-essential amino acid ratios. In: D'MELLO, J.P.F. Amino acids in animal nutrition. 2.ed. Edinburgh: CABI Publishing, 2003. p.103-124.

LE BELLEGO, L.; NOBLET, J. Performance and utilization of dietary energy and amino acids in piglets fed low protein diets. Livestock Production Science, v.76, n.1-2, p.45-58, 2002 . 
LILBURN, M.S. [2003]. Protein quality of whole spent hens coextruded with corn or wheat compared with soybean meal or meat and bone meal. Great Plains Protein, LLC. Disponível em: $<$ http://www.greatplainsprotein.com/research_trials_animal_ nutrition.php>. Acesso em: 5/12/2007

MOSENTHIN R.; RADEMACHER, M. Digestible amino acids in diet formulation for pigs. In: D'MELLO, J.P.F. (Ed.) Amino acids in animal nutrition. 2.ed. Edinburgh: CABI Publishing, 2003. p.169-186.

MOUGHAN, P.J.; FULLER, M.F. Modelling amino acid metabolism and the estimation of amino acid requirements. In: D'MELLO, J.P.F. (Ed.) Amino acids in animal nutrition. 2.ed. Edinburgh: CABI Publishing, 2003. p.187-202.

NATIONAL RESEARCH COUNCIL - NRC. Nutrient requirement of swine. 10.ed. Washington, D.C.: National Academy of Sciences, 1998. 189p.

NOBLET, J. [2003]. Impact of dietary crude protein on metabolic utilization of energy in pigs. In: LATIN AMERICAN COLLEGE OF ANIMAL NUTRITION, 2003. Engormix.com, Community of International Business Related to Animal Production. Disponível em: <http://www.engormix.com/e_articles.asp?ID=100>. Acesso em: 5/11/2007

PEKAS, J.C.Versatible swine laboratory apparatus for physiologic and metabolic studies, Journal of Animal Science, v.27, n.5, p.1303-1306, 1968.

ROTH, F.X.; EDER, K.; RADEMACHER, M. et al. Effect of apparent ileal digestible lysine to energy ratio on performance growing pigs at differet dietary metabolizable energy levels. Journal of Animal Phisiology and Animal Nutrition, v.83, n.4-5, 181-192, 2000.

SALTER, D.N.; MONTGOMERY, A.I.; HUDSON, A. et al. Lysine requirements and whole-body protein turnover in growing pigs. British Journal Nutrition, v.63, n.3, p.503-13, 1990.
STATISTICAL ANALYSIS SYSTEM - SAS. User's guide: statistics. Version 6.12. Cary: Statistical Analysis System Institute, 1996. (CD-ROM).

THACKER, P,A, Nutritional requirementes of erarly weaned pigs: a review, Pig News Information, v.20, n.1, 13N-24N, 1999.

TOKACH, M.D.; DRITZ, S.S.; DE ROUCHEY, J.M. et al. Effects of increasing dietary lysine in phase II diets (15 to $25 \mathrm{Lb}$ ) on nursery pig growth performance. Swine Day, p.43-46, 2003.

TOKACH, M.D.; PETTIGREW, J.E.; JOHNSTON, L.J. et al. Effect of adding fat and (or) milk products to the weaning pig diet on performance in nursery and subsequent grow-finishing stages. Journal of Animal Science, v.73, n.11, p.3358-3368, 1995.

TRINDADE NETO, M.A., BARBOSA, H.P., PETELINCAR,I.M. et al. Dietas para leitões nas fases de creche e diferentes idades ao desmame. Revista Brasileira de Zootecnia, v.31, n.2, p.672-680, 2002.

TRINDADE NETO, M.A.; KRONKA, R.N.; BARBOSA, H.P. et al. Níveis de lisina para suínos na fase inicial-I do crescimento, desempenho e retenção de nitrogênio. Boletin de Indústria Animal, v.57, n.1, p.65-74, 2000.

URYNEK, W., BURACZEWSKA, L. Effect of dietary concentration and apparent ileal digestible lysine: metabolizable energy ratio on nitrogen balance and growth performance of young pigs. Journal of Animal Science, v.81, p.1227-1236, 2003.

Van LUNEN, T.A.; COLE, D.J.A. The effect of dietary concentration and lisien/digestible energy ratio on growth performance and nitrogen deposition of young hybrid pigs. Animal Science, v.67, n.1, p.117-129, 1998.

WILLIAMS, N.H.; STAHLY, T.S.; ZIMMERMAN, D.R. Effect of chronic immune system activation on the rate, efficiency, and composition of growth and lysine needs of pigs fed from 6 to 27 kg. Journal of Animal Science, v.75, n.9, p.2463-71, 1997. 